\title{
ADMINISTRAÇÃO POLÍTICA DA SAÚDE: UMA ANÁLISE DAS AÇÕES EM SAÚDE NO MUNICÍPIO DE CAMPINA GRANDE, PARAÍBA
}

POLITICAL ADMINISTRATION OF HEALTH: AN ANALYSIS OF THE HEALTH ACTIONS OF IN THE COUNTRY OF CAMPINA GRANDE, PARAÍBA

\section{Kleiton Wagner Alves da Silva Nogueira'}

RECEBIDO: 03/12/2018 | ACEITO: 06/05/2019

DOI: $10.5902 / 2317175835886$

\section{RESUMO}

O Sistema Único de Saúde (SUS) é tido como uma conquista da sociedade brasileira. Compreender que esse sistema se caracteriza como uma política de Estado é considerar que há uma administração política da saúde em vigor. Nesse contexto, entende-se que o planejamento se torna central para esse sistema, por fornecer ferramentas para um pensar em longo prazo ao gestor público. Nessa perspectiva, o SUS possui, como parte integrante de sua gestão, o sistema de Planejamento do SUS (PlanejaSUS), que através de instrumentos básicos, como planos, programações e relatórios, permite ao sistema planejar metas, diretrizes e ações em saúde. Dessa forma, o objetivo do presente estudo foi analisar a execução do Plano Municipal de Saúde do município de Campina Grande referente à gestão de 2014 a 2017, por intermédio dos instrumentos de planejamento. Caracterizada como uma pesquisa exploratória, descritiva e documental, os principais resultados obtidos evidenciaram pouca atenção dada às metas analisadas, assim como para o próprio Plano Municipal de Saúde, que demonstrou servir como peça burocrática.

Palavras-chave: Gestão em saúde; Planejamento em saúde; Administração política.

1 Bacharel em Administração pela Universidade Estadual da Paraíba (2017); licenciado em Geografia pela Universidade Federal de Campina Grande (2013). Atualmente é bolsista pelo Programa de Pós-graduação em Ciências Sociais pela Universidade Federal de Campina Grande na linha de pesquisa: Desenvolvimento, Ruralidades e Políticas Públicas. Integrante do Grupo de Estudo e Pesquisa Sobre Estado e Luta de Classes na América Latina (PRÁXIS); Grupo de Pesquisa em Geografia para Promoção da Saúde (PRÓ-SAÚDE GEO); Grupo de Pesquisa sobre o Nordeste (GPNE). 
ADMINISTRAÇÃO POLIITICA DA SAÚDE:

UMA ANÁLISE DAS AÇÕES EM SAÚDE NO MUNICÍPIO DE CAMPINA GRANDE, PARAíBA

\begin{abstract}
The Unified Health System (SUS) is considered as an achievement of Brazilian society. What is it is a system as a state policy that there is a health policy in place. In this context, in order to carry out the planning is fundamental to the system, with the aim of providing a long term for public management. In this perspective, SUS has, as an integral part of its management, the SUS Planning System (PlanejaSUS), which is based on basic programs such as: plans, programs and reports, providing the system, health plan goals, goals and actions. Thus, the present study was analyzed for the execution of the Municipal Health Plan of the city of Campina Grande, in 2014, through the planning instruments. It was characterized as an exploratory, descriptive and documentary research, the results of the results evidenced an attention given as goals analyzed, as well as for the Municipal Health Plan itself, which proved to serve as a bureaucratic piece.
\end{abstract}

Keywords: Health planning; Health political administration of; Health management.

\title{
1 Introdução
}

O Sistema Único de Saúde (SUS) é considerado uma política de Estado, pois trabalha com a concepção do direito à saúde de forma universalizada. Entende-se que, através do planejamento e da descentralização da gestão, esse sistema está inserido nos mais variados territórios do Brasil (ANDRADE, 2001; PAIM, 2009; AGUIAR, 2011a;). Pela dimensão e complexidade do território brasileiro, o planejamento é tido como uma ferramenta que subsidia o gestor público na tomada de decisões e na resolubilidade de problemas de saúde que afetam a sociedade de uma forma geral. (MINISTÉRIO DA SAÚDE, 2008). O planejamento, enquanto elemento central da Administração, demonstra a preponderância dessa ciência para a sociedade, tendo em vista que, a gestão das relações sociais de produção no capitalismo necessita do planejamento como uma forma de pensar as melhores formas de se atingir objetivos propostos pela própria sociedade (RIBEIRO, 2006; MATOS, 2008; SANTOS 2009; TEIXEIRA, 2016).

Ao refletir sobre a relação entre planejamento, política, gestão e gerência, Medeiros Júnior (2017) destaca que no SUS existe o que ele denomina por administração política da saúde. Na interpretação desse autor, o SUS além de ser uma política de Estado, possui elementos de gestão que fornecem um pensar em longo prazo sobre ações e serviços de saúde. Contudo, ao mesmo tempo em que existe esse pensar, por outro lado, há a problemática do subfinanciamento crônico, ou seja, da ausência de recursos para a plena concretização desse planejamento (MENDES, 2012; MENDES; FUNCIA, 2016). Diante desse contexto, o planejamento no SUS é fundamental, pois com ele, é possível tecer metas e ações em saúde que levam em consideração os problemas reais da sociedade. Para o correto subsídio do planejamento no SUS, encontramos na legislação brasileira instrumentos de planejamento em saúde, como plano municipal de saúde, programação anual em saúde e relatório anual de gestão, que fornecem uma forma de organizar e sistematizar essas ações e metas no nível federal, estadual e municipal (MINISTÉRIO DA SAÚDE, 2008). 
Frente a essa reflexão, o presente artigo procura abordar de que forma esses instrumentos de planejamento são adotados em uma escala local. Procura-se entender até que ponto o plano municipal de saúde do município de Campina Grande, referente à gestão de 2014 a 2017, vem contribuindo para a efetivação da política pública de saúde nesse município. A escolha desse cenário de estudo não foi feita de forma deliberada, pois Campina Grande foi um dos primeiros municípios do Brasil a adotar o processo de descentralização na gestão do SUS na década de 1990, bem como pioneiro em implantar o Programa Saúde da Família, sendo um município de porte médio que agrega serviços de saúde da baixa a alta complexidade. Como um meio de refletir sobre esse questionamento, objetivamos analisar a execução do plano municipal de saúde mais recente, por intermédio das programações anuais de saúde e dos relatórios anuais de gestão à luz da Administração Política. Essa análise é importante, pois o planejamento no SUS ainda é um desafio para boa parte das gestões municipais, que tentam lidar diariamente com os problemas de saúde. Segundo o Ministério da Saúde (2008), cerca de 90\% dos municípios de 100 mil até 500 mil habitantes utilizam o planejamento através do plano municipal de saúde para pactuarem metas e ações em saúde. Esse percentual cai gradativamente de acordo com municípios que possuem demografias inferiores a 100 mil habitantes. Além disso, o planejamento é considerado por muitos gestores públicos como peça burocrática, não sendo usado de forma efetiva na gestão (LUZ; PEREIRA; SILVA, 2012). À vista disso, refletir sobre a Administração nessa perspectiva é evidenciar o papel dessa ciência para além do âmbito micro organizacional, é uma forma de abrir espaço para o administrador pensar os problemas da sociedade, ao entender que esse profissional tem a capacidade de olhar a realidade de forma crítica.

\section{Referencial Teórico}

\subsection{Arcabouço Legal do Sistema Único de Saúde}

De acordo com Paim (2009), o fato de existir um Sistema único de Saúde em um país de dimensões continentais como o Brasil, por si só, é uma conquista para a sociedade brasileira. De acordo com o referido autor, a criação desse sistema levou em consideração a ideia do direito à saúde em caráter universal. Nesse ínterim, o SUS é caracterizado por um conjunto de ações e serviços públicos, organizados de forma hierarquizada em todo o território brasileiro, sendo assegurado por normas, leis, princípios e diretrizes. Segundo Solha (2014) o SUS é pautado nos seguintes princípios: universalidade; integralidade; equidade; participação popular; hierarquização; regionalização; e descentralização. Cada um desses elementos, juntamente com as normas e legislações, guiam os gestores públicos na administração desse grande e complexo sistema. Ao considerarmos esses aspectos, percebemos que a gestão do SUS precisou obrigatoriamente de um lastro jurídico que oferecesse suporte à 
ADMINISTRAÇÃO POLITIICA DA SAÚDE:

tomada de decisão por parte da administração pública. Por se entender o SUS como uma política de Estado, um conjunto de elementos normativos foram elaborados pelos diferentes governos para que, assim, fosse possível, em um plano institucional, assegurar uma gestão mais efetiva (AGUIAR, 2011b).

Com a criação da lei 8.080/1990 o SUS passa a ter uma sistematização mais concreta de fato. Essa lei é caracterizada como a lei orgânica da saúde. O seu Art. $2^{\circ}$ considera que saúde é um direito fundamental do ser humano, devendo o Estado prover as condições indispensáveis ao seu pleno exercício. Nessa lei, estão especificados os objetivos do SUS, princípios, diretrizes, direção, organização, gestão do sistema e especificações das funções da união, estados e municípios. Ainda em 1990, com a Lei $n^{\circ} 8.142 / 1990$ se tem a criação de instâncias colegiadas para participação da comunidade na gestão, essa lei criou a conferência nacional de saúde e os conselhos de saúde. Na gestão do sistema, essas instâncias são muito importantes, uma vez que, inserem a perspectiva da participação democrática na gestão para a tomada de decisão.

Em 1991, com a norma operacional básica $n$. $^{\circ} 91$ o SUS ganha diretrizes referentes ao funcionamento da cobertura ambulatorial, estabelecimento da criação dos fundos de saúde para estados e municípios, requisitos básicos para as transferências automáticas e diretas de recursos de custeio para os municípios, bem como, deliberações a respeito de consórcios intermunicipais em saúde. Contudo, é no ano de 1993 com a norma operacional básica nº 93, que há o processo de descentralização das ações e serviços de saúde. A descentralização é entendida como a redistribuição de poder e redefinição de papéis no estabelecimento de novas relações entre as três esferas de governo. No ano de 1996, a partir da norma operacional básica n 96, há a consolidação da descentralização em função da importância do ente municipal e seu território na condução das políticas públicas de saúde. Para o Ministério da Saúde (1997), o município é o responsável imediato pelo atendimento das necessidades e demandas de saúde da população. Essa mesma norma estabelece o conceito de gerência e gestão do sistema municipal de saúde. A gerência implica na administração de uma unidade ou órgão de saúde (ambulatório, hospital, instituto, fundação etc.) que se caracteriza como prestador de serviços ao SUS. A gestão, por sua vez, seria mais ampla que a gerência, podendo ser caracterizada como a atividade de dirigir um sistema de saúde mediante o exercício de funções de coordenação, articulação, negociação, planejamento, acompanhamento, controle, avaliação e auditoria.

Com o aumento da população dos centros urbanos e consequente complexidade dos problemas de saúde da sociedade para além dos territórios municipais, passa a existir a necessidade de se pensar em estratégias regionais para resolução desses problemas. Dessa forma, no ano de 2001 com a norma operacional da assistência à saúde (NOAS-2001), a questão da regionalização em saúde é inserida como elemento importante no processo de gestão. Para o Ministério da Saúde (2001), com o processo de aprofundamento da descen- 
tralização promovido pelas normas anteriores, a regionalização é parte importante para a promoção da saúde, uma vez que, busca a organização de sistemas de saúde que envolva todos os níveis de atenção para além dos limites territoriais de um determinado município.

Como uma forma de garantir mais acesso da população a serviços e ações de saúde, a NOAS-2001 aborda três grupos de estratégias articuladas que visam contribuir para o processo de regionalização em saúde como forma de promover a descentralização com equidade no acesso: elaboração do plano diretor de regionalização; fortalecimento das capacidades gestoras do SUS e Atualização dos critérios e do processo de habilitação de estados e municípios. Todavia, com a necessidade de realizar uma atualização em mecanismos institucionais que acompanhassem a complexidade tanto da evolução da sociedade, dos territórios, como da própria necessidade de fortalecer a gestão do sistema, em 2006 é lançado o pacto pela saúde. Esse pacto surge com o objetivo de promover inovações em processos e instrumentos de gestão para uma maior eficiência do sistema.

Segundo o Ministério da Saúde (2006a), o pacto pela saúde é formado por três eixos: a) pacto pela vida; b) pacto em defesa do SUS e c) pacto de gestão do SUS:

O pacto pela vida está constituído por um conjunto de compromissos sanitários, expressos em objetivos de processos e resultados e derivados da análise da situação de saúde do País e das prioridades definidas pelos governos federal, estaduais e municipais. [...] O Pacto em Defesa do SUS envolve ações concretas e articuladas pelas três instâncias federativas no sentido de reforçar o SUS como política de Estado, mais do que política de governos; e de defender, vigorosamente, os princípios basilares dessa política pública, inscritos na Constituição Federal. [...] O Pacto de Gestão estabelece as responsabilidades claras de cada ente federado de forma a diminuir as competências concorrentes e a tornar mais claro quem deve fazer o quê, contribuindo, assim, para o fortalecimento da gestão compartilhada e solidária do SUS. (MINISTÉRIO DA SAÚDE, 2006a, p. 02).

Pode-se considerar que, com o pacto pela saúde, há de fato o entendimento de que o SUS é maior do que simples projeto de governo, podendo ser considerado como uma política de Estado.

Em 2011, com o Decreto 7.508/2011, há a regulamentação da lei orgânica de saúde. Esse decreto reafirma a importância de elementos como: contrato organizativo da ação pública da saúde; portas de entrada; comissões intergestores; mapa da saúde; rede de atenção à saúde; protocolo clínico e diretriz terapêutica. Como fator preponderante para a gestão do sistema, o decreto considera que as portas de entrada às ações e aos serviços de saúde nas redes de atenção à saúde são: a) atenção primária; b) atenção de urgência e emergência; c) atenção psicossocial e d) especiais de acesso aberto. Esse decreto 
ADMINISTRAÇÃO POLITITICA DA SAÚDE:

também reafirma, em seu Art. 15, que o processo de planejamento da saúde será ascendente e integrado, ouvindo os respectivos conselhos de saúde e, compatibilizando as necessidades das políticas de saúde com a disponibilidade de recursos financeiros.

A partir desta breve exposição acerca dos elementos institucionais do SUS, entendemos que o planejamento é parte essencial do trabalho do gestor público de saúde. Essa concepção deriva do fato de que não adianta ter elementos normativos e jurídicos que firmem o SUS como uma política de Estado se o gestor não consegue pensar de forma planejada em estratégias que meIhor possam atender às demandas da sociedade. Nesse contexto, no próximo tópico, será possível visualizar como se promove o processo de planejamento no SUS e qual a sua real importância para a gestão pública.

\subsection{Instrumentos de Planejamento e Gestão do SUS}

O Ministério da Saúde (2009a) aponta que o processo de gestão em saúde é uma tarefa complexa, que exige capacitação e visão holística por parte dos gestores em saúde. No âmbito do SUS, é possível observar um esforço na implantação da cultura do planejamento mediante o Sistema de Planejamento do SUS (PlanejaSUS). Esse sistema é regulamentado pela Portaria $n^{\circ} 3.085 / 2006$ - revogada pela portaria $n^{\circ}$ 2.135/2013 -, por intermédio da qual o Ministério da Saúde trabalha no sentido de viabilizar ações da união, estados e municípios. O funcionamento do PlanejaSUS deve ser realizado de forma harmônica em todas as esferas do sistema, com observância dos processos pactuados e definidos, respeitando assim, o papel a ser desenvolvido por cada esfera de governo, com atenção às peculiaridades e às realidades vivenciadas por cada uma. Nesse sentido, o PlanejaSUS trabalha através de instrumentos básicos de gestão que auxiliam os gestores públicos a organizarem e planejarem a política pública de saúde nos territórios sob sua administração. É possível identificar três instrumentos básicos de gestão: o plano de saúde; programação anual em saúde e o relatório anual de gestão.

O plano de saúde é caracterizado como um instrumento que tem por base uma análise situacional, do qual apresenta intenções e os resultados a serem atingidos durante um período de quatro anos esboçados em objetivos, diretrizes e metas. A análise situacional do plano deve levar em consideração três eixos principais: a) condições de saúde da população; b) determinantes e condicionantes de saúde e c) gestão em saúde. Diante disso, pode-se considerar o plano de saúde como a materialização das políticas e dos compromissos de saúde em uma determinada esfera de gestão perante necessidades reais da sociedade. Esse instrumento é a base para a execução, o monitoramento, a avaliação e a gestão do SUS (MINISTÉRIO DA SAÚDE, 2007; 2009b). A programação anual em saúde é um instrumento que operacionaliza as intenções expressas no plano de saúde. Nesse instrumento são detalhadas as metas anuais 
e os recursos financeiros que operacionalizam o plano de saúde. A programação anual de saúde contém as programações de áreas específicas. $O$ relatório anual de gestão, por sua vez, é o instrumento que apresenta os resultados alcançados com a execução da programação anual de saúde. Ao término do período do plano de saúde, é necessária a realização de uma avaliação no sentido de exibir os resultados alcançados para que, então, se tenha subsídios para a elaboração de um novo plano de saúde, com os devidos ajustes e inserção de novos quadros (MINISTÉRIO DA SAÚDE, 2009b).

Esses instrumentos são essenciais para a manutenção e organização das ações em saúde, além disso, dão suporte para a tomada de decisão por parte do gestor público, fornecendo também, resultados para uma retroalimentação de informações para futuros planejamentos (MINISTÉRIO DA SAÚDE, 2006a; SILVA, SANTOS, MENDES, 2012). Portanto, os instrumentos de planejamento do SUS fazem parte de um quadro maior de gestão pública. Nessa perspectiva, visualizamos a administração política como esse quadro que tem na intervenção estatal um pensar em longo prazo sobre elementos estruturais da sociedade brasileira. Sendo assim, o próximo tópico é dedicado a explorar de forma breve o conceito de administração política e sua relação com a saúde pública brasileira.

\subsection{A Administração Política e sua Relação com a Gestão}

Ribeiro (2006) levanta a noção de que a Administração é uma ciência social e que o administrador é mais do que um simples executor de tarefas. Esse profissional deve ir além dos aspectos técnicos de sua formação, tendo em vista que a natureza do desempenho de sua atividade possui relações políticas permeadas por interesses e correlações de poder.

Ao refletir sobre a perspectiva da política como vocação, Weber (2004) destaca que as relações sociais são políticas no sentido de que haverá sempre, em seu cerne, interesses, conservação ou transferência de poder. Dessa forma, o homem vive em um ambiente político, de modo que, a sua própria história é política. Não existe uma civilização apolítica, nem muito menos indivíduos apolíticos. Para Durkheim (2007), o homem é um ser sociável, que não pode isolar-se a não ser estando inserido em sociedade. Nesse contexto, Marx ([1860] 2008), considera que a forma como os homens produzem é determinada socialmente através da produção social dos meios de existência humana. A visão desses três clássicos da Sociologia nos mostra o quanto a relação entre poder, sociedade e indivíduo se faz presente em uma estrutura de dominação, imbricada por interesses e teias de acesso referentes à produção da materialidade social. Dessa forma, considerar que a Administração e a política sempre mantiveram uma real implicação na forma como os homens planejavam, organizavam e pensavam em formas de se viver em sociedade, é um raciocínio plausível e pautado na própria formação das sociedades. 
ADMINISTRAÇÃO POLIITICA DA SAÚDE:

UMA ANÁLISE DAS AÇÕES EM SAÚDE NO MUNICÍPIO DE CAMPINA GRANDE, PARAíBA

Etimologicamente, ao se investigar a palavra Administração é possível observar que em sua composição já é nítido o componente político, como destaca Santos, Ribeiro e Chagas (2009):

\begin{abstract}
Para uma melhor compreensão do significado da palavra administração é necessário separar os seus termos: o prefixo "ad" quer dizer para (próximo de aproximar, abeirar, achegar) enquanto o núcleo (verbo) "ministrar" quer dizer conduzir, dar, fornecer. (...) administração quer dizer transformar, conduzir para..., direção de (SANTOS, RIBEIRO, CHAGAS, 2009, p. 927, grifos nossos).
\end{abstract}

O ato de transformar e conduzir em direção de algo subjaz que as relações sociais estão permeadas por interesses e relações de poder que se materializam na forma como os homens organizam, produzem, distribuem, fazem circular e consomem os recursos produzidos na sociedade. Com isso, inerente ao ato de transformar e conduzir, a política estaria caracterizada como a relação na qual indivíduos, organizações, estados e instituições de um modo geral, manterão no campo social, que, por sua vez, está carregado de intencionalidades e relações de poder dentro de um campo político. Nesse bojo, a administração não foge a essa realidade, mesmo que se considerem relações formais e burocráticas pautadas na eficiência, eficácia e efetividade dos processos administrativos.

De acordo com Santos e Ribeiro (1993) a Administração sendo política tem, por objeto de estudo, a gestão, dessa forma, esse campo do saber se concretiza pela forma como o Estado se organiza para realizar a manutenção das relações sociais de produção.Nesse caso, a Administração é, por constituição de sua natureza, administração política, ou seja, por ser uma ciência que constantemente está trabalhando com a concepção de gestão dos recursos produzidos pela divisão social do trabalho, a forma como essa ação é realizada tem por sua vez intencionalidade e objetivo. Nesses moldes, Santos (2009) salienta que para um melhor entendimento do que venha a ser administração política seria necessário realizarmos uma comparação com a economia política, no sentido de que se possa perceber o real objetivo e função da Administração enquanto ciência:

[...] devemos pôr a administração política em confronto com a economia política. Desse modo, se a economia política, no plano da materialidade humana, responde pelo "que" e "por que" fazer, ou seja, pelas possibilidades da produção, da circulação e da distribuição de bens materiais, a administração política tende a responder pelo "como" fazer, ou seja, pela concepção do modelo de gestão para se chegar à finalidade. Conceber a gestão da materialidade das relações sociais constitui o objeto, portanto a essência, da administração. Aqui temos o campo próprio da ciência da administração: a administração política (SANTOS, 2009, p. 45, grifos nossos). 
Entender que a administração política representa a gestão da materialidade das relações sociais de produção, preocupada na forma de como fazer essa gestão, fica mais claro refletir que essa ciência supera a mera esfera tecnicista, podendo assim contribuir com análises e estudos para além das relações micro organizacionais. A administração política, nesses termos, passa a trabalhar com os dilemas e problemas da própria sociedade. É nesse sentido que se entende o papel estratégico do administrador político para a formação de uma materialidade que consiga subsidiar a sociedade de forma plena, uma vez que, esse profissional possui a capacidade de refletir acerca de uma sociedade, na qual exista a possibilidade de acesso à materialidade necessária para o desenvolvimento humano.

Mediante essa reflexão, é possível compreender que essa ciência tem um papel primordial no desenvolvimento da sociedade. Todavia, ao passo que se reflete sobre o objeto da Administração política - gestão -, um questionamento de base epistemológica surge: o que se entende por gestão? Para Santos, Ribeiro e Chagas (2009), a gestão implica no ato de gerir e desenvolver as relações sociais de produção, realização e distribuição em qualquer momento histórico da humanidade. Para estes autores, a gestão seria a dimensão abstrata da administração política. Nesse limiar, o papel do administrador político está ligado ao ato de trabalhar em formas de realizar a gestão dos recursos a fim de modificar uma determinada realidade, superando assim o tecnicismo oriundo da concepção neoclássica da economia, na qual o administrador seria aquele profissional responsável apenas por atividades técnicas em prol de uma eficiência no uso dos recursos dentro das organizações.

Conforme Silva e Lopes (2009), o administrador deve ser considerado como um cientista social e gestor dos recursos da sociedade e das organizações, fazendo uso da tomada de decisão em consonância com o cenário apresentado e os objetivos pretendidos. Ou seja, esse cientista social, gestor dos recursos sociais é o administrador político. Para que seja possível compreender esse pressuposto, devemos ter cautela na diferenciação entre gestão e gerência. A gerência estaria ligada a uma concepção aplicada da administração política. Dessa forma, a gerência; ao possuir um caráter prescritivo, trabalha no cumprimento de deliberações de uma determinada concepção de gestão.

[...] gerenciar, gerência - trata-se do lugar onde se exerce ou executa as funções (os processos, a engenharia, enfim) das relações sociais de produção e distribuição, também, em qualquer contexto e momento histórico do processo civilizatório. Com isso, impõe-se de forma clara uma distinção entre gestão (concepção) e gerência (execução): base profissional da dimensão abstrata da administração (SANTOS; RIBEIRO; CHAGAS, 2009, p. 928, grifos nossos).

Nesse contexto, reflete-se que a gerência faz parte da execução de um ato pensando na gestão. Com isso, a administração política estaria preocupa- 
ADMINISTRAÇÃO POLIITICA DA SAÚDE:

da em conceber um modelo de gestão para a garantia da materialidade humana. Essa administração política seria formada por duas dimensões: uma abstrata, a qual competiria à gestão dessas relações sociais de produção; e outra, aplicada correspondente aos atos de conceber e gerenciar (BARRETO, 2011).

A partir dessa visão, é possível visualizar o administrador político como responsável pela gestão, e o administrador profissional ligado à concepção de gerência. É importante salientar que esses dois polos não são mutuamente excludentes. A administração profissional é tão importante quanto à administração política, uma vez que, sem as técnicas de gerência, a concepção de gestão de um determinado projeto encontraria dificuldades para o seu real desenvolvimento e efetivação. Ou seja, os âmbitos do concreto e do abstrato da administração política devem fazer parte de um todo (SANTOS 2009). Para Barreto (2011), tanto o administrador político quanto o administrador profissional são importantes por trabalharem de forma interdependente com as concepções de gestão e gerência. Segundo Santos (2009), a Administração profissional compreende os profissionais ligados à execução de um determinado projeto, que, no caso da reflexão do autor, remete a um projeto de nação. Com isso, tem-se que além do bacharel em administração, outros profissionais também podem ser considerados como administradores profissionais:

[...] administração profissional compreende todos aqueles profissionais que direta ou indiretamente estão responsáveis pela execução do projeto da nação. Aqui estamos falando do economista, do médico, do pedagogo, do filósofo, do arquiteto, do administrador, do engenheiro, do pedreiro, do carpinteiro, do motorista, enfim, de todos os profissionais requeridos na construção daquele projeto de sociedade (SANTOS, 2009, p. 49, grifos nossos).

Contudo, é importante elencar que o bacharel em administração, por formação, seria o especialista mais qualificado para assumir cargos de gestão e de gerência. A esse modo, compreende-se que, em princípio, a formação em administração deve congregar elementos básicos para o entendimento dos processos que ocorrem no seio de uma determinada sociedade, dando ao profissional desta área, habilidades e competências específicas para o trato com os dilemas e desafios da gestão e da gerência.

\section{Metodologia}

\subsection{Método de Abordagem}

A partir do objetivo proposto neste estudo, a pesquisa caracteriza-se como exploratória e descritiva. Segundo Gil (2002), a pesquisa exploratória fornece um contato mais familiar entre o pesquisador e o problema a ser pesquisado, para que seja possível a realização de um maior aperfeiçoamento em 
torno das ideias ou descobertas que o pesquisador terá. Já a vertente descritiva tem a função de descrever as características de um fenômeno, fazendo assim correlações entre variáveis. No que diz respeito aos procedimentos técnicos de coletas de dados, o estudo é enquadrado como bibliográfico e documental, uma vez que se utilizou como bibliografia: livros; capítulos de livros e artigos científicos; assim como documentos de ordem primária como: plano municipal de saúde; programação anual em saúde e relatório anual de gestão.

\subsection{Cenário do Estudo}

O município de Campina Grande está localizado no Estado da Paraíba, distante cerca de $130 \mathrm{~km}$ da capital do Estado, João Pessoa. Segundo dados do IBGE (2017), Campina Grande é considerada capital regional B, categoria que caracteriza o município de acordo com o nível hierárquico na rede urbana do Estado da Paraíba (SPÓSITO; SOARES, 2013).Campina Grande possui relevância preponderante no desenvolvimento regional do Estado da Paraíba, em especial, por estar localizado no interior do Estado, onde, através da sua rede de influência, consegue estender produtos e serviços para as demais cidades menores, criando uma rede de articulação. Medeiros Júnior, Santos e Souza (2012) destacam que esse município foi um dos primeiros municípios do Brasil a adotar o processo de municipalização em saúde, implicando assim, na autonomia que a gestão deste município passou a ter diante dos serviços e ações de saúde.

Além destes fatores, ao observar-se o referencial teórico adotado neste estudo, entende-se que Campina Grande se caracteriza como um laboratório para a visualização de aspectos relacionados à gestão e à gerência do SUS, uma vez que os estudos de Rotta (1997); Medeiros Júnior $(1999,2017)$ apontam que o município já, na década de 1990, apresentava um modelo de gestão caracterizado como hospitalocêntrico privado. Dessa forma, ao ter essa evidência, parte-se do entendimento que investigar como se efetiva o planejamento tendo como base instrumentos como plano de saúde, programação anual em saúde e relatório anual de gestão pode fornecer pistas sobre a forma como o planejamento vem contribuindo para a efetivação da política pública de saúde no município, em que direção caminha a gestão municipal e se há uma administração política da saúde no município.

\subsection{Produção de Dados e Informações}

Foram coletados documentos oficiais de gestão e planejamento em saúde: plano municipal de saúde referente à gestão de 2014 até 2017. É importante salientar que o plano tem duração de quatro anos, sua escolha em específico ocorreu pois foi o mais recente executado pela administração pública do município. Outros documentos consultados foram às programações anuais de saúde e os relatórios anuais de gestão dos anos de 2014; 2015; 2016 e 2017. 
Cabe destacar que, devido a essa imensa quantidade de metas e indicadores que o plano municipal de saúde possui, foi necessária a realização de uma seleção de metas que teve como norte a base teórica fornecida pelo Ministério da Saúde, assim como em autores que trabalham com a Administração política e a gestão do SUS. Com isso, o estudo utilizou os três eixos de estruturação para seleção das metas: a) condições da saúde da população; b) determinantes e condicionantes em saúde e c) gestão em saúde.

Nessa etapa também foi necessário à observância dos seis grandes blocos de financiamento do Sistema Único de Saúde de modo a se ter uma melhor sistematização do que foi planejado no município. Conforme aponta Brasil (2015) há seis blocos: a) atenção básica; b) atenção de média e alta complexidade ambulatorial e hospitalar; c) vigilância em saúde; d) assistência farmacêutica; e) gestão do SUS; f) investimentos na rede de serviços de saúde. Ao todo, foram selecionadas um total de 32 metas através de uma amostragem não probabilística referente ao universo de metas existe no plano municipal de saúde.

\subsection{Procedimentos de Análise}

Com a seleção das metas, o estudo utilizou-se da análise documental onde se realizou a observância do que foi planejado para cada meta, e o que de fato foi executado, tendo como parâmetro os indicadores utilizados pelo plano municipal de saúde. Cabe salientar que a análise referente às metas selecionadas teve como fonte de dados o próprio plano municipal de saúde, assim como as respectivas programações anuais e relatórios anuais de gestão.

De acordo com Moreira (2005), é fundamental que a análise documental tenha por escopo a criticidade no intuito de fomentar uma avaliação criteriosa. Essa autora indica como procedimentos para a análise documental a seguinte sequência: a) caracterização e descrição dos documentos; b) elaboração de anotações e comentários sobre o conteúdo do documento; c) tratamento das informações coletadas e d) interpretação da informação;

Para a presente pesquisa, a análise se processou da seguinte forma: em um primeiro momento, os documentos recolhidos foram organizados e selecionados com base em sua modalidade. Após a etapa de caracterização, foram selecionadas as metas no plano municipal de saúde para sua correspondente avaliação quanto ao processo de evolução e comportamento das metas selecionadas tanto nas programações anuais quanto nos relatórios anuais de gestão durante a gestão de 2014 até 2017, ou seja, durante quatro anos de execução do plano de saúde. Com a organização, sistematização e verificação das informações foi possível realizar interpretações acerca da utilidade dos instrumentos de planejamento em saúde, assim como, identificar os elementos e dinâmicas da gestão e da gerência em saúde para o recorte analítico adotado. 


\section{Apresentação e Discussão dos Resultados}

Essa sessão está subdividida em três partes: a primeira procura caracterizar o plano municipal de saúde estudado onde se procurou realizar ponderações acerca da sua formulação e aspectos que chamaram atenção na análise. Na segunda parte, há a sistematização e análise das metas selecionadas coforme explanado na metodologia, por meio do qual, foi possível identificar o comportamento das metas e sua associação com o planejamento. Por último, procurou-se viabilizar um nexo entre teoria, observação e prática relacionada à temática do planejamento e da administração política, tendo por base elementos da gestão e da gerência em conformidade com os pressupostos teóricos adotados no trabalho.

\subsection{Caracterização do Plano Municipal de Saúde}

O plano municipal de saúde de Campina Grande foi elaborado por uma equipe representativa de órgãos oficiais da área da saúde no município, tais como: vigilância sanitária; direção administrativa financeira do município; gerência de informação em saúde; conselho municipal de saúde; diretoria de planejamento e regulação; gerência de regulação; assessoria técnica de regulação; atenção básica municipal; gerência de vigilância ambiental e zoonoses; como também gerência financeira.

O processo de construção do plano foi realizado com a elaboração de grupo condutor, criado a partir da Portaria $n^{\circ} 40 / 2013$. Esse grupo, em sua composição, tinha quadros das áreas técnicas da secretaria municipal de saúde, representantes da sociedade civil organizada e membros do conselho municipal de saúde. Segundo a secretaria municipal de saúde (2014), foram realizadas nove audiências públicas; uma em cada um dos seis distritos sanitários e uma em cada distrito administrativo do município (Campina Grande possui um total de três distritos administrativos). Essas reuniões procuraram organizar as demandas da sexta conferência municipal de saúde realizada no ano de 2011.

Para o conhecimento das condições de saúde da população, foram utilizados dados sobre o perfil demográfico e socioeconômico do município. Um dos pontos que chama atenção nessa caracterização é o uso de dados sem fontes e dados que remetem ao ano de 2000 , como a proporção de moradores com instalações sanitárias e proporção de moradores por tipo de coleta de lixo. Dados com esse tempo de defasagem podem representar em termos de gestão um problema, devido à necessidade de o planejamento ser construído com base em informações atualizadas e que corresponda à realidade, em última instância, o planejamento tem por papel cumprir objetivos que alteram aspectos materiais da realidade vigente.

No item referente aos dados epidemiológicos, percebe-se que os dados utilizados, tiveram como fonte o Departamento de Informática do SUS (DATASUS). 
ADMINISTRAÇÃO POLITITICA DA SAÚDE:

Esses dados fazem referência ao ano de 2011. Cabe destacar que dados dessa magnitude são publicados anualmente o que significa que o plano, supostamente, deveria usar no mínimo dados do ano de 2012. Dessa forma, com base no plano, cerca de $29,81 \%$ dos óbitos ocorridos em Campina Grande foram ocasionados por doenças do aparelho circulatório, seguido das neoplasias com 15,95\% e doenças endócrinas, nutricionais e metabólicas com $13,50 \%$. Ademais, chama atenção o fato de que, no texto do plano, há menção aos dados do DATASUS do ano de 2012, porém o que se verifica de fato é que esses dados foram do ano de 2011.

No que diz respeito aos dados de morbidade hospitalar, observou-se que $22,27 \%$ das internações estão ligadas à gravidez; $25,21 \%$ relacionadas a doenças do aparelho respiratório, $12.61 \%$ a doenças infecciosas e parasitárias e $8 \%$ das internações causadas por problemas no aparelho circulatório. Os dados relativos a essas informações são do ano de 2013, o que causa dúvida, tendo em vista que os dados do ano de 2013 não estavam disponibilizados no banco de informações do SUS no momento de discussão da elaboração do plano (que em tese deveria ser no ano de 2013). Destaca-se ainda nesse item que o plano utilizou-se apenas de dados sobre mortalidade e morbidade hospitalar. Nesse caso, sentiu-se a necessidade de um maior detalhamento no que diz respeito aos dados sobre cobertura vacinal, monitoramento da qualidade da água, índice de infestação do Aedis argypti, quantitativo de pessoas com hanseníase, tuberculose e doenças sexualmente transmissíveis.

O plano destaca que Campina Grande possui uma Estratégia de Saúde na Família (ESF) que cobre $84,92 \%$ de seu território, com um total de 595 Agentes Comunitários de Saúde (ACS) distribuídos na rede de atenção básica. Esses agentes conseguem contemplar um total de $87,83 \%$ da população do município. Segundo a Secretaria Municipal de Saúde de Campina Grande (2014), no município, existem cerca de 70 Unidades Básicas de Saúde (UBS) com 10 ancoras, sendo 7 UBS em área rural e 3 em área urbana. Nessas UBS, atuam 96 Equipes de Saúde da Família (ESF) e 13 equipes do Programa de Agentes Comunitários de Saúde (PACS). Embora o Plano Municipal de Saúde mostrasse a existência dessas 96 equipes da ESF, a análise evidenciou que a soma total contabiliza 101 equipes. $O$ mesmo equívoco apresenta-se em relação às equipes do PACS que, no texto do plano, são 13 e em outros momentos do mesmo plano, apresentam-se com um total de 7 equipes. Outro elemento que chama atenção é o fato que um total de 78 UBS estarem inscritas no cadastro nacional de estabelecimento de saúde e não 70 como o plano coloca. De acordo com o plano, o município conta ainda, com cerca de 9 Núcleos de Apoio à Saúde da Família (NASF). Esses núcleos possuem: nutricionista; fisioterapeuta; farmacêutico, educador físico e psicólogo. Além do NASF, Campina Grande aderiu ao Programa 
de Melhoria de Acesso e da Qualidade da Atenção Básica (PMAQ) com a adesão de 91 equipes da Atenção Básica, 48 equipes da Saúde Bucal e 9 NASF.

De modo geral, o plano analisado apresenta alguns problemas de ordem organizacional e de análise situacional, o que demonstra certa negligência sobre informações úteis ao bom planejamento. Chamamos atenção para esse fato porque o plano serve como uma estrutura comum na elaboração de metas a serem atingidas; se o plano não é enfático, objetivo e completo, certamente, algumas lacunas reverberarão na execução do que foi planejado. Nos tópicos a seguir, será possível visualizar a execução das metas selecionadas na metodologia do estudo, como uma forma de entender como a gestão municipal vem trabalhando com os instrumentos de planejamento em saúde.

\subsection{Os Blocos de Ações em Saúde: Entre o Planejado e o Executado}

Através do procedimento metodológico adotado, foi possível verificar que, das trinta e duas metas selecionadas para análise, seis foram classificadas como alcançadas, onze metas foral alcançadas parcialmente, cinco metas não foram alcançadas e cerca de seis metas não foram passíveis de identificação devido à ausência de informações nos documentos pesquisados. Chama atenção o grau de metas alcançadas de forma parcial, ou seja, que não foram alcançadas em sua plenitude. Esse dado está intimamente associado a uma dificuldade encontrada na pesquisa: determinadas metas aparecem de forma diferente nos três instrumentos de planejamento, dificultando assim, o entendimento de qual meta seria a correta.

O planejamento não deve ser encarado como uma camisa de força, tão pouco como um documento imune a alterações, contudo, se faz importante o correto detalhamento, explicação e apontamentos sobre mudanças de metas ou estratégias que levaram ao abandono e ao cumprimento parcial. Os instrumentos de planejamento do SUS conforme os apontamentos do Ministério da Saúde (2006a) refletem a lógica de um instrumenta que procura viabilizar uma cultura organizacional voltada ao planejamento para a tomada de decisões e não como mera peça burocrática a ser cumprida sem uma finalidade. Desse modo, essa constatação demonstra que, em princípio, não houve uma revisão dos relatórios anuais de gestão, o que vem a corroborar as pesquisas já realizadas sobre o tema, que foram desenvolvidas pelo Ministério da Saúde (2008); Luz, Pereira e Silva (2012); Silva, Santos e Mendes (2012).

No bloco da atenção básica, por exemplo, ao considerarmos que o município de Campina Grande foi um dos primeiros a adotar o Programa de Saúde na Família (PSF), hoje denominado Estratégia de Saúde na Família, esperava-se que, em princípio, os dados sobre cobertura territorial das equipes de atenção básica estivessem completos em $100 \%$. Os resultados demonstraram que, no plano organizativo, metas como a construção de unidades básicas de saúde e o ajustamento de unidades existentes em imóveis próprios foram alcançadas de forma parcial, contudo, sem haver uma explicação plausível sobre o não cumprimento total dessa meta. Esse resultado apenas demonstra o movimento histórico e estrutural da forma como o município encara a questão da promoção à saúde. 
ADMINISTRAÇ̃̃O POLÍTICA DA SAÚDE:

Junto a esse bloco da atenção básica, incluiu-se também, metas importantes referentes ao bloco de investimentos, tendo em vista que, boa parte das metas selecionadas diziam respeito a esfera desse bloco. Dessa forma, na verificação realizada constatou-se que, a não construção de UBS e a inadequação completa de estruturas físicas dessas unidades em imóveis próprios, traduz a dificuldade do município em lidar com a atenção básica de modo estratégico. A ampliação e a adequação de UBS subjazem mais qualidade e acessibilidade a serviços básicos por parte da sociedade. Conforme já mencionado, pensar estrategicamente no melhoramento da atenção básica é possuir o entendimento que muitas das demandas das filas de hospitais poderiam ser resolvidas nos próprios bairros. Isso resultaria na demanda por serviços de média e alta complexidade de forma mais organizada o que diminuiria o fenômeno das longas filas de espera do SUS.

Historicamente, como Medeiros Júnior (2017) destaca, há uma ausência de um projeto de administração política no município de Campina Grande que coaduna com as premissas de uma saúde mais universal, assim como proposto pelo SUS. Segundo esse autor, a gestão do município concentra boa parte dos seus gastos com a esfera privada/hospitalar. É perceptível que essa concentração de recursos influencia em um não desenvolvimento da atenção básica no município. Salienta-se que não é possível desconsiderar a importância deste tipo de atenção, contudo, em termos de gestão e de um pensar em torno de uma Administração política da saúde, seria mais viável e estratégico investir na atenção básica. Este investimento começaria pela totalidade da cobertura das equipes de atenção básica, assim como na completa estruturação desse serviço, o que viria a melhorar a qualidade do serviço ofertado à população. Em uma visão que coaduna com a nossa perspectiva teórica, ter conhecimento desses elementos, tendo como subsídio o planejamento, ofereceria ao gestor público, a capacidade de canalizar as demandas dos serviços hospitalares para serem resolvidas nas próprias UBS. Por isso, reafirma-se a importância detratar o planejamento não como elemento burocrático, mas, como metodologia para a promoção de informações a gestão pública.

No bloco referente á atenção de média e alta complexidade, a ausência de informações sobre as metas de ampliação de procedimentos ambulatoriais, a instalação da Unidade de Pronto Atendimento (UPA) do tipo II, a ampliação da rede própria de análises clínicas e o pouco avanço nas metas referentes à instalação de policlínicas nos distritos sanitários implica que o município deixa de implantar serviços importantes para a comunidade. Além desse fato, a implementação ou a ampliação de serviços como o da UPA, rede própria de análises clínicas, significaria uma maior autonomia do município frente ao setor privado. Como ocorreu no bloco anterior, a ausência de informações, ou pontos difusos sobre a evolução dessas metas chama atenção. Foi possível observar, por exemplo, que, algumas metas foram apenas planejadas para um determinado ano, sendo que nos relatórios dos anos posteriores tais metas 
continuaram a aparecer sem nenhum tipo de indicação de cumprimento ou não, o que causa dúvidas sobre como planejar ações posteriores.

É preciso salientar que os instrumentos de planejamento do SUS devem ser vistos de forma interdependente, ou seja, se temos um plano de saúde que cobre uma gestão de quatro anos conforme estamos analisando, as respectivas programações anuais em saúde e os relatórios anuais de gestão são também, documentos importantes, que foram criados para subsidiar ações no decorrer da gestão como um todo. Pela observação realizada na análise, esses documentos são tratados de forma desvinculada, sem uma conexão plausível e sem o reaproveitamento de informações. Ou seja, há uma divisibilidade por ano, na qual, constatou-se uma ausência de diálogo entre os documentos que compõem como um todo, o planejamento em saúde no município para a gestão analisada.

No bloco da vigilância sanitária, salienta-se o cumprimento de metas importantes como a cobertura vacinal BCG e rotavírus em $90 \%$ das crianças nos dois primeiros anos da gestão $(2014,2015)$, para o ano de 2016 a meta não foi alcançada e em 2017 não foi possível encontrar informações a respeito dessa meta. Chama atenção nesse bloco, o fato de algumas metas mudarem tanto no que diz respeito às programações anuais, quanto nos relatórios anuais. Há metas que mudam de indicador sem uma explicação plausível, aliado a esse elemento, também se encontra o fato do alcance de metas de forma parcial, ou seja, não completadas em sua plenitude. Citamos o caso da meta relacionada à oferta de tratamento supervisionado para $100 \%$ dos pacientes em tratamento de tuberculose. Nessa meta em específico, não há uma clara definição do que foi alcançado. Em muitos casos, como foi possível observar o histórico da meta, algumas informações parecem estar fora de contexto, ou se apresentam de forma vaga, o que não oferece nenhum subsídio ao ato de planejar e pensar em novas ações.

O bloco da Assistência Farmacêutica se mostrou como um dos mais complexos em termos de ausência de informações. Todas as metas selecionadas para análise no presente estudo não foram possíveis de identificação quanto ao cumprimento devido à ausência de informações. Nesse bloco, destacam-se metas importantes para o atendimento de demandas como: funcionamento dos serviços de assistência farmacêutica; melhoramento de espaço físico da farmácia central e atendimento de demandas judiciais. É importante destacar que, as demandas judiciais se tornaram um problema sério conforme o próprio plano municipal de saúde aponta em sua análise situacional. Contudo, o que se evidencia é que, mesmo considerando esse como um problema que merece resolução, não há informações concretas sobre esses problemas. $\mathrm{O}$ que se identificou foram metas parciais de acordo com os anos, sem uma conexão mais ampla com a gestão para os quatro anos da gestão.

Diante da análise realizada, constatamos que a gestão, através das informações produzidas com os instrumentos de planejamento, não consegue 
ADMINISTRAÇÃO POLITITICA DA SAÚDE:

ter total acesso e visão, tanto em termos quantitativos quanto qualitativos, às metas planejadas. Destaca-se que uma análise mais apurada, tendo como base nos relatórios anuais de gestão, poderia fornecer subsídios para que o município diminuísse gastos com demandas judiciais, uma vez que, essas demandas influenciam no gasto de recursos com medicamentos que poderiam ser substituídos por outros com preços mais acessíveis. Contudo, não apenas o desencontro de informações chama atenção, mas o próprio fato de existir a impressão de que esse tema é tratado de forma periférica pela gestão municipal fica nítido, metas como instalação de farmácias populares, garantia de serviços de assistência farmacêutica não sendo passível de observação devido a ausência de informações, aparece como elemento problemático para a real efetivação da avaliação do que está sendo planejado e o que vem sendo executado.

O bloco de Gestão em Saúde possui metas importantes para a modernização e implantação de uma cultura de planejamento no município e também aparece de forma incompleta. A ausência de informações não permitiu observar o andamento de metas importantes que iriam influenciar de forma positiva no melhoramento da gestão em saúde no município. Nesse bloco, destaca-se que as metas selecionadas na análise iriam trazer celeridade e maior participação de forma descentralizada da comunidade frente à gestão das ações de saúde a serem desenvolvidas. Isso poderia trazer benefícios para a gestão municipal de saúde local, uma vez que o SUS tem como preceito o caráter participativo na comunidade frente às demandas por serviços de saúde. Avalia-se que as metas da Gestão em Saúde deveriam ter recebido uma maior atenção e melhor tratamento das informações presentes no relatório. Essa ausência dificulta pensar em formas de melhoria na gestão municipal de saúde.

O bloco de Gestão em Saúde, em especial, chama atenção pelas suas propostas. O fato de haver como propostas elementos, como a manutenção de uma cultura de planejamento, participação democrática e ampliação da estrutura tecnológica na gestão, que subsidiariam uma melhor tomada de decisão e consequente fortalecimento dos instrumentos de planejamento no município. O fato de existir dentro do plano municipal de saúde metas associadas à esfera do planejamento, que, em sua prática e processo avaliativo, se apresentam de forma periférica, demonstra que a gestão municipal precisa evoluir no tratamento e importância dada a essa esfera.

De um modo geral, a sensação em torno do recorte analítico que se teve acesso na pesquisa, demonstra lacunas importantes e provam que o município ainda precisa avançar no uso dos instrumentos de planejamento do SUS, para que assim, possa pensar a longo prazo em estratégias e metas de um programa duradouro em saúde que vise beneficiar a população. No tópico a seguir refletimos sobre essa necessidade tomando por base elementos teóricos do planejamento e sua associação com uma possível administração política em saúde. 
4.3 A Necessidade do Plajemento na Construção de uma Administração Política da Saúde

Dentro do âmbito epistemológico da administração enquanto ciência possui como objeto de estudo a gestão, o planejamento é um eixo central para a reflexão em torno dos procedimentos e linhas de ações a serem tomadas dentro de uma organização. Nesse sentido, conforme reflexão realizada por Santos, Ribeiro e Chagas (2009), Barreto (2011) e Santos (2009), a Administração possui uma dimensão abstrata ligada à gestão e uma aplicada referente à gerência. É importante salientar que tais dimensões não estão dissociadas e muito menos desvinculadas uma da outra. Essas duas instâncias são sumariamente importantes para o sucesso de qualquer projeto ou ações pensadas em longo prazo.

Os resultados obtidos através da análise do presente estudo demonstram justamente a importância da gestão e da gerência na promoção de uma administração política da saúde, ou seja, de um projeto de saúde que trabalhe de forma planejada em curto, médio e longo prazo. Ao compreender que o SUS, em um plano institucional, apresenta bons instrumentos de planejamento e gestão como o PlanejaSUS, fica entendido que a materialização de tais instrumentos está intimamente conectada à forma como as gestões municipais, estaduais ou federais lidam com esse instrumento. No caso do plano municipal de saúde de Campina Grande, para a gestão de 2014 até 2017, foi possível constatar, com base em elementos empíricos, conforme metodologia adotada, que o planejamento em saúde, bem como a sua execução, toma um corpo mais tecnicista, como uma espécie de cumprimento de obrigações. Diante das trinta e duas metas analisadas e acompanhadas durante os quatro anos de gestão, o fato de se ter onze metas alcançadas de forma parcial, dez metas não identificadas devido à inconstância de informações e cinco metas não alcançadas demonstra a necessidade de um maior amadurecimento por parte da gestão municipal no tocante ao planejamento em saúde.

Chama atenção que, mesmo em uma concepção burocrática, as informações contidas nos relatórios anuais de gestão oferecerem dificuldades para - gestor ter condições de analisar, avaliar e programar ações futuras em saúde. Essa evidência também serviu para mostrar que tanto o plano municipal de saúde quanto às programações anuais e os relatórios anuais de gestão são tratados de forma mecânica e dissociados, o que promove justamente uma visão de não totalidade sobre as metas elencadas e consequente intervenção na realidade. Dessa forma, para além da ausência de informações referentes às metas planejadas, constata-se, conforme Medeiros Júnior (2017), a inexistência no município de um modelo de gestão em saúde em longo prazo, ou seja, de uma administração política da saúde. $O$ fato de termos uma concentração de recursos na média e alta complexidade também evidencia a forma como a promoção à saúde é levada em consideração no plano municipal de saúde. 
ADMINISTRAÇ̃̃O POLÍTICA DA SAÚDE:

Além desses fatores, a análise também releva uma maior necessidade de trabalhar a cultura do planejamento em âmbito municipal. Fica perceptível que os instrumentos de planejamento funcionam como uma espécie de modelo a ser preenchido com pouca reflexão acerca da real necessidade de se trabalhar com a ideia do planejamento em saúde. Nesse sentido, mediante os resultados obtidos nesta pesquisa, pode-se refletir como hipótese que a ausência de informações referentes à execução de metas e ações traduz uma gerência que dá pouca atenção ao processo de acompanhamento e execução do Plano de Saúde. Considera-se que isso acaba por influenciar de forma negativa na gestão municipal. Parte-se do pressuposto que a Gestão e a Gerência são suas esferas que precisam estar em sintonia.

Esses resultados traduzem uma linguagem em que, mesmo dentro de uma visão de curto prazo, o município apresenta problemas relacionados a uma concepção burocrática, que se materializam mediante a pouca atenção e o não acompanhamento das metas pactuadas no planejamento. Nesse sentido, este estudo conseguiu perceber que, além dos problemas de gerência, Campina Grande também possui problemas de gestão, por não conseguir uma continuidade em suas políticas, dando ao SUS um caráter de política de Estado orientada por programas de governo.

\section{Considerações Finais}

A administração política, ao considerar a gestão como objeto de estudo, traz ao debate epistemológico o fato dessa ciência ter um objeto de estudo próprio, que abre novas possibilidades para que o administrador se insira na análise de problemas e dilemas da sociedade, tornando esse profissional um agente ativo na sociedade. Nesse trabalho, evidenciou-se que a gestão do SUS está ligada diretamente por instrumentos que conferem informações e detaIhes para o gestor público. Entretanto, ao enxergar o SUS como um sistema, é preciso ter em mente a sua complexidade e dimensão, pois tentar visualizar essa política de Estado a partir de um único viés é ter uma noção reducionista. Nesse sentido, com o acompanhamento, avaliação e reflexão das metas programadas para a gestão na saúde do município de Campina Grande, pretendeu-se realizar uma ponte entre o aporte teórico da administração política com o uso de duas principais categorias: gestão e gerência relacionadas ao planejamento mediante o sistema de planejamento do SUS aplicado a uma realidade local.

Ao se trabalhar com essas duas categorias, foi possível evidenciar o SUS como uma política de Estado que, mesmo possuindo problemas cotidianos, caracteriza-se como uma política pensada a longo prazo pelo Estado brasileiro. Entretanto, ao trazer esse panorama para uma análise local, buscou-se seguir o raciocínio da própria administração política: de que as pesquisas em administração devem se esforçar em compreender e explicar a realidade, ligando 
as escalas micro e macro de análise para que seja possível evidenciar de melhor forma os problemas da realidade.

Tendo em vista os resultados obtidos na pesquisa, compreende-se a contribuição desse estudo em torno de uma reflexão associada à administração para além de um campo técnico e executivo. Outra contribuição sumária que a pesquisa oferta é a possibilidade de pensar a própria gestão em saúde no município de Campina Grande, bem como em outros municípios, tendo em vista que o estudo pode ser replicado em outras realidades locais com as devidas mediações, podendo inclusive, servir de aporte para as gestões e avaliações de planos de saúde no Brasil de uma forma geral. Além desses elementos, os resultados obtidos neste estudo podem contribuir para a oferta de informações para análises junto à secretaria municipal de saúde. Considerando uma perspectiva mais aprofundada, com uso de outras técnicas de pesquisa como entrevistas e análise de grupo focal, entrevistas para que se entenda, de fato, quais são as maiores dificuldades de adotar esses instrumentos de planejamento como ferramentas para a gestão municipal de Campina Grande e não apenas como peças burocráticas junto aos técnicos e ao pessoal da gestão que lida diretamente com o planejamento em saúde.

Para não esgotarmos a discussão, salienta-se também a necessidade de pesquisas futuras que realizam a ponte entre os instrumentos democráticos de gestão em saúde como o conselho municipal de saúde, instância na qual, os instrumentos de planejamento do SUS passam por avaliação, no sentido de analisar a forma como dentro dessa esfera, o plano municipal de saúde é visto e debatido pelos respectivos conselheiros. De forma geral, este estudo demonstra que é preciso encarar a administração a partir de um viés crítico, tendo em vista que o papel do administrador é também questionar a realidade e se aprofundar sobre temas que são inerentes à sociedade, não aceitando a realidade pela aparência e consciência ingênua, mas, mergulhando de forma crítica com uma consciência crítica sobre a essência dos fatos.

\section{Referências}

AGUIAR, Z. N. Antecedentes históricos do Sistema Único de Saúde (SUS) - breve história da política de saúde no MS. In: AGUIAR, Z. N. SUS: antecedentes, percurso, perspectivas e desafios. São Paulo: Martinari, 2011a, p. 15-40.

AGUIAR, Z. N. O Sistema Único de Saúde e as Leis Orgânicas da Saúde. In: AGUIAR, Z. N. SUS: antecedentes, percurso, perspectivas e desafios. São Paulo: Martinari, 2011b, p. 41-68.

ANDRADE, L.O.M. SUS passo a passo: gestão e financiamento. São Paulo: Hucitec, 2001.

BARRETO, S.S. A construção da 'Administração Política' e suas contribuições para a Ciência da Administração. REBAP. Revista Brasileira de Administração Política, v. 4, p. 77-97, 2011.

BOURDIEU, P. Capítulo VII: a representação política elementos para uma teoria do campo político. In. BOURDIEU, P.. O poder simbólico. 13ª ed. Rio de Janeiro: Bertrand MS. 2010, p. 163 - 202.

DURKHEIM, É. Sociologia e Filosofia. $2^{\text {a }}$ ed. São Paulo: Ícone, 2007.

GIL, A. C. Como elaborar projetos de pesquisa. 3. ed. São Paulo: Atlas, 2002. 
ADMINISTRAÇÃO POLÍTICA DA SAÚDE:

UMA ANÁLISE DAS AÇÕES EM SAÚDE NO MUNICÍPIO DE CAMPINA GRANDE, PARAíBA

IBGE. INSTITUTO BRASILEIRO DE GEOGRAFIA E ESTATÍSTICA. Regiões de influências das cidades, 2017.

LUZ, A. B. C; PEREIRA, M.F; SILVA, M.L.B. Análise dos instrumentos de planejamento do Sistema Único de saúde (SUS). 2012. Monografia. (Aperfeiçoamento/Especialização em Especialização em gestão da saúde pública) - Universidade Federal de Santa Catarina. Orientador: Maurício Fernandes Pereira.

MARX, K. Contribuição à crítica da Economia Política. Introdução e tradução de Florestan Fernandes. $2^{a}$ ed. São Paulo: Expressão Popular, [1860] 2008.

MEDEIROS JÚNIOR, G G. Economia e Administração Política da Saúde: Análise das Dinâmicas do Capital e do Estado na Gestão do SUS no Brasil e em Campina Grande. Tese de doutorado. Programa de PósGraduação em Planejamento Urbano e Regional da Universidade Federal do Rio de Janeiro - UFRJ, 2017.

MEDEIROS JÚNIOR, G. Desafios da Municipalização da saúde: Evolução do Fundo Municipal de Saúde e Perspectivas de Implementação de um Novo Modelo de Saúde em Campina Grande. 1999. 130 f. Dissertação (Mestrado em Economia) - Universidade Federal da Paraíba.

MEDEIROS JÚNIOR, G; SANTOS, A.L.S; OLIVEIRA, M.P; SOUZA;T.A.P. A política de saúde no município de Campina Grande: uma análise sobre a execução do Plano Municipal de Saúde. [Relatório PIBIC]. Universidade Estadual da Paraíba, 2012.

MENDES A, FUNCIA F. R. O SUS e seu financiamento. In: Marques, R.M; Piola, S.F; Roa, A.C (org). Sistema de Saúde no Brasil: organização e financiamento. Rio de Janeiro: ABrES, 2016, p. 139 - 168.

MENDES, Á. N. Tempos turbulentos na saúde pública brasileira: os impasses do financiamento no capitalismo financeirizado. São Paulo: Editora Hucitec, 2012.

MINISTÉRIO DA SAÚDE. Norma Operacional Básica do Sistema Único de Saúde/NOB-SUS 96.Brasília: MS, 1997.

MINISTÉRIO DA SAÚDE. Portaria n 399 de 22 de fevereiro de 2006: Divulga o Pacto pela Saúde. Diário Oficial da União, 2006a.

MINISTÉRIO DA SAÚDE. Portaria $\mathbf{N}^{\circ} \mathbf{3 . 3 3 2}$, de $\mathbf{2 8}$ de dezembro de 2006. Aprova orientações gerais relativas aos instrumentos do Sistema de Planejamento do SUS. Brasília; 2006b.

MINISTÉRIO DA SAÚDE. Portaria n 837, de 23 de Abril de 2009. Altera e acrescenta dispositivos à Portaria $n^{\circ}$ 204/GM, de 29 de janeiro de 2007, para inserir o Bloco de Investimentos na Rede de Serviços de Saúde na composição dos blocos de financiamento relativos à transferência de recursos federais para as ações e os serviços de saúde no âmbito do Sistema Único de Saúde - SUS, 2009b. Disponível em: < http://bvsms. saude.gov.br/bvs/saudelegis/gm/2009/prt0837_23_04_2009.html > Acesso em: Mar. 2017.

MINISTÉRIO DA SAÚDE. Secretaria de Assistência à Saúde. Regionalização da assistência à saúde: aprofundando a descentralização com eqüidade no acesso: Norma Operacional da Assistência à Saúde: NOAS-SUS 01/01 e Portaria MS/GM n.o 95, de 26 de janeiro de 2001 e regulamentação complementar. Brasília: MS, 2001.

MINISTÉRIO DA SAÚDE. Sistema de Planejamento do SUS : uma construção coletiva: organização e funcionamento . 3. ed. Brasília: MS, 2009a. (Série Cadernos de Planejamento).

MINISTÉRIO DA SAÚDE. Sistema de Planejamento do SUS: Uma construção coletiva: Avaliação do desenvolvimento do Plano Nacional de Saúde - 2004-2007: Um pacto pela saúde no MS. Brasília: MS; 2007.

MINISTÉRIO DA SAÚDE. Sistema de planejamento do SUS: uma construção coletiva: perfil da atividade do planejamento no Sistema Único de Saúde: resultados da pesquisa - esfera municipal. Secretaria Executiva, Subsecretaria de Planejamento e Orçamento. Brasília; 2008.

MOREIRA, S. V. Análise documental como método e como técnica. In: DUARTE, J; BARROS, A (Org.). Métodos e Técnicas de Pesquisa em Comunicação. São Paulo: Atlas, 2005. p. 267-279.

PAIM, J.S. O que é o SUS. Rio de Janeiro: Fiocruz, 2009.

MATOS, E.R. Revisitando o conceito de administração política. Revista Brasileira de Administração Política, v. 1, n. 1, 2008. 
RIBEIRO, João Ubaldo. Política e Administração. O \& S, Salvador, v. 13, n. 38, p.167-198, 01 jul. 2006.

ROTTA, J. H. As relações quantitativas do SUS em Campina Grande e o processo de Municipalização da Saúde. Mestrado em Economia, UFPB. Série Debates, n. 68, ago. 1997.

SANTOS, R. S. S; GOMES, F. G. Outro modo de interpretar o Brasil - ensaios de uma Administração Política: Caminhos para a construção do projeto nacional. São Paulo: Hucitec, 2017.

SANTOS, R. S.; RIBEIRO, E. M. A administração política brasileira. Revista de Administração Pública, Rio de Janeiro, v. 27, n. 4, p. 102-135, out./dez. 1993

SANTOS, R. S.; RIBEIRO, E.M ; CHAGAS, T. Bases Teórico-Metodológicas da Administração Política. Revista de Administração Pública, v. 4, p. 919-941, 2009.

SANTOS, R.S. Em busca da apreensão de um conceito para administração política. In: SANTOS, Reginaldo (org.). Administração Política como campo do conhecimento. São Paulo-Salvador: Hucitec-Mandacaru, 2009, p. 23-61.

SECRETARIA MUNICIPAL DE SAÚDE. Prefeitura Municipal de Campina Grande. Plano Municipal de Saúde: 2014 2017, 2014.

SILVA, D. N.; LOPES, P. F. S. . O papel do administrador: administrar, gestar ou gerir?. Revista Brasileira de Administração Política, v. 2, p. 65-78, 2009.

SILVA, K.C.L; SANTOS, E. R. R; MENDES, M. S. O planejamento estratégico no processo de implementação da política de atenção primária em um município da região metropolitana do Recife, Pernambuco, MS. JMPHC. Journal of Management and Primary Health Care, v. 3, p. 15-25, 2012.

SOLHA, R.K.T. Sistema único de Saúde: componentes, diretrizes e políticas públicas. São Paulo: Érica, 2014.

SPÓSITO, M. E. B; SOARES, B. R. (org). Agentes econômicos e reestruturação urbana e regional: Campina Grande e Londrina. São Paulo: Outras Expressões, 2013.

TEIXEIRA, F.L.C. Administração política: surge um novo paradigma de pesquisa em área contestada. Revista Brasileira de Administração Política, v. 1, n. 1, 2016.

WEBER, M. Ciência e política: duas vocações. São Paulo: Cultrix, 2004. 